\title{
WinPSSP: a computer program applying direct-space methods for the crystal structure solution of small molecule organic solids from X-ray powder diffraction
}

\author{
S. Pagola, ${ }^{1}$ A. Polymeros, ${ }^{2}$ and N. Kourkoumelis ${ }^{3}$ \\ ${ }^{1}$ Department of Applied Science, College of William \& Mary, Williamsburg, VA, USA. ${ }^{2}$ Department of Physics, \\ University of loannina, 45110, loannina, Greece, ${ }^{3}$ Department of Medical Physics, Medical School, University of \\ Ioannina, 45110, loannina, Greece.
}

Since late 1980's direct-space methods have radically changed the scope of powder diffraction, nowadays including crystal structure solution. However, the topic is young, with less than 300 structures published before 1999 [1]. To disseminate the crystal structure determination methods from powders, it has been proposed to improve the average academic training in crystallography, and to increase the user friendliness of the software [1]. Towards this end, we have made available a Windows OS version of the direct-space methods program PSSP (running in MS_DOS mode) [2], to solve the crystal structures of small molecule organic solids, as well as instructional videos expected to be useful for undergraduates and inexperienced users. WinPSSP [3] is freely downloadable at http://users.uoi.gr/nkourkou/winpssp. The software, which works together with the program GSAS [4] for Le Bail fits and Rietveld refinement, and this particular practical implementation of the direct-space methods will be discussed. Crystal structure determination examples will be shown, reviewing the procedure, difficulties and facilitations using WinPSSP.

[1]- A. Le Bail et al., Powder Diffraction (2009) 24:3, 254-262. [2]- S. Pagola and P. W. Stephens, J. Appl. Cryst. (2010) 43, 370-376. [3]- S. Pagola, A. Polymeros and N. Kourkoumelis, J. Appl. Cryst. (2017) 50, 293303. [4] Larson, A. C. and von Dreele, R. B. General Structure Analysis System (GSAS). Los Alamos National Laboratory Report: New Mexico, USA 2004. 